\title{
Temperature conditions of hothouses during a warm season
}

\author{
Valery Bodrov ${ }^{1, *}$, Mikhail Bodrov ${ }^{1}$, Kirill Lushin $^{2}$ \\ ${ }^{1}$ Federal State Budgetary Educational Institution of Higher Professional Education « Nizhny \\ Novgorod State University of Architecture and Civil Engineering (NNSUACE)», Russia \\ ${ }^{2}$ Moscow State University of Civil Engineering, Russia
}

\begin{abstract}
On the basis of justification of the heat and mass transfer processes inside the hothouses during a warm season authors developed methods and means that control dynamics of temperature and humidity parameters and air conditions with the help of complex systems of removal of overheat in the hothouses during the all year round and diurnal operations at minimum power inputs.
\end{abstract}

\section{Introduction}

Under the climatic conditions of sharply continental climate in most regions of Russia growing vegetables in the cold season is only in winter hothouses. Exploitation of winter hothouses in the warm season is difficult due to overheating of the air inside of them because of the increased intensity of solar radiation. Crop losses in this period can reach $50 \ldots 80 \%$, and sometimes there is a destruction of plants.

The authors have developed a complex system of removal of overheat in the hothouses in the warm season. Given technique consists in use for the longest period of natural (passive) systems providing microclimate parameters (transoms, technological openings, aeration shaft) and for short-term inclusion of active systems, their key elements are the systems of water aerosol cooling (SWAC). While the system of water aerosol cooling the water is spraying in the whole volume of the hothouse through the nozzles, and during the adiabatic evaporation water lowers the temperature of the internal air.

We studied six typical modes of a complex system of heat removal to ensure acceptable temperature parameters of air in hothouses: mode I - an organized natural ventilation; mode II - co-operation of the systems of organized natural ventilation and active aeration; mode III - co-operation of the mechanical ventilation and natural ventilation; mode IV - cooperation of the SWAC and natural ventilation; mode V - co-operation of the SWAC, natural ventilation and active aeration; mode VI - co-operation of the SWAC, natural ventilation and mechanical ventilation.

Dynamics of changes in air temperature in an unventilated, with closed openings and transoms, hothouse with plants in the warm season is shown on the $i-d$-diagram of humid air (fig. 1).

\footnotetext{
${ }^{*}$ Corresponding author: unirs@nngasu.ru
} 
In the early morning hours the air temperature in the hothouse with plants in the phase of cultivated biomass $t_{i n t}^{m}$ is close to or slightly higher than the outside air temperature $t_{\text {ext }}^{m}$ (point $H^{m}$ ), relative air humidity $\varphi_{i n t}^{m} \rightarrow 100 \%$ (point $B^{m}$ ). On the inner surface of translucent enclosures of hothouses we can observe condensate. In this period of the day the temperature $t_{i n t}^{m}$ can be below, equal to or higher than the design temperature, shown in figure 1 by the hatched area (1) with temperature gradient $\Delta t_{\text {calc }}$.

The point $B^{d}$ with the parameters $t_{i n t}^{d}, \varphi_{i n t}^{d}$, the moisture content $d_{\text {int }}^{d}, \mathrm{~g} / \mathrm{kg}$ of dry air, enthalpy of $i_{i n t}^{d}, \mathrm{~kJ} / \mathrm{kg}$, shows the air condition in the hothouse during daylight hours in the absence of ventilation (area 3). The air temperature $t_{i n t}^{d}$ is increased by solar radiation and significantly exceeds the allowable values. Such temperature conditions in hothouses arise in the climate conditions of central part of Russia, starting from mid-April.

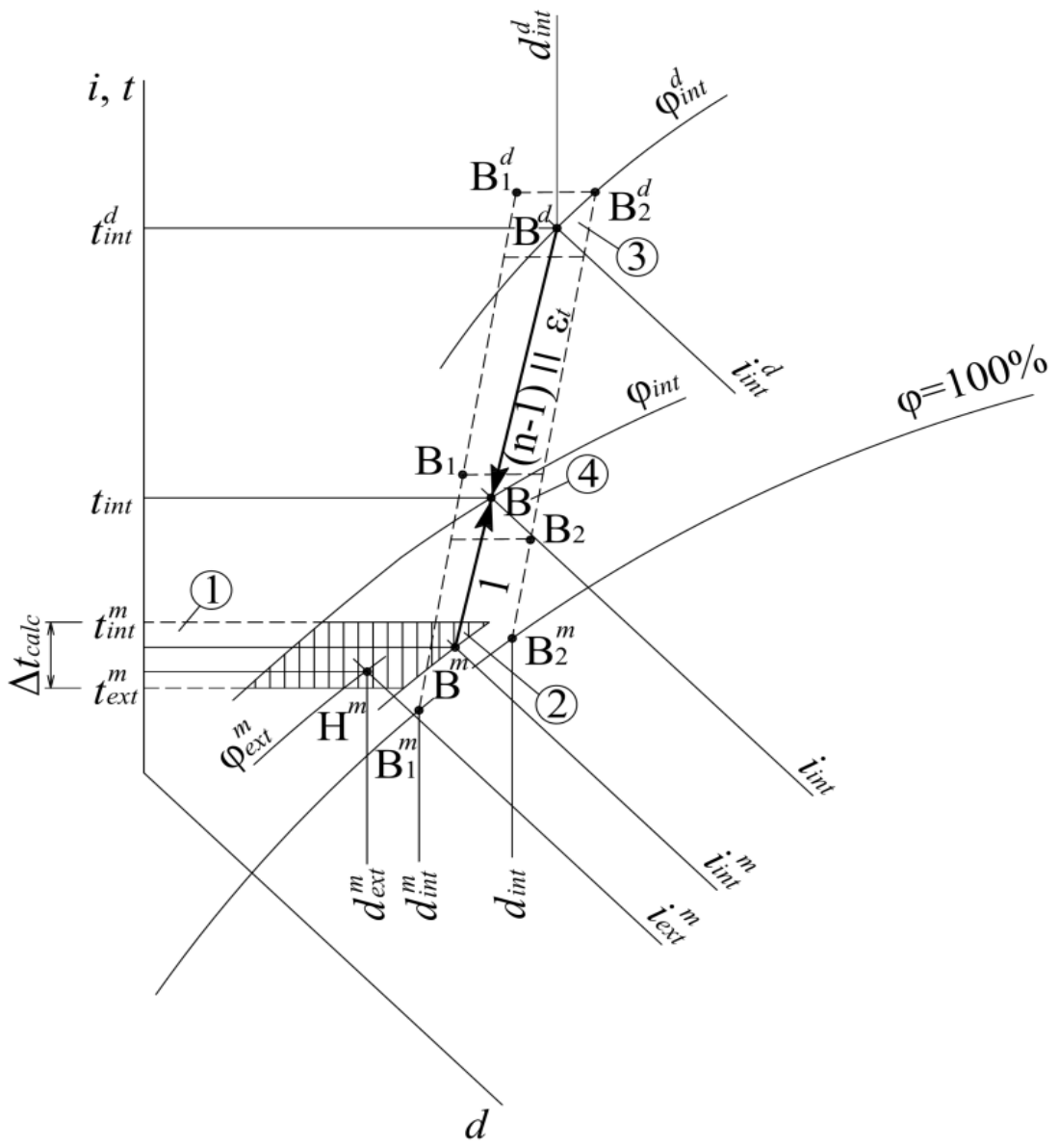

Fig. 1. The area of self-regulation of the temperature in the hothouse when the untreated air supply: 1 - the area of technological temperatures in the hothouse; 2 - the area of the temperatures during the morning hours; 3 - the area of maximum temperatures in the absence of ventilation; 4 -the area of possible temperatures when the outdoor air ventilation 
In the first approximation consider that the parameters of internal air (point $B$ ) lie on the line $B^{m}-B^{d}$, that is the geometric position of the points of the air state in the unventilated hothouses.

The first stage of reducing the air temperature is organized natural ventilation of the hothouse by opening transoms (mode $I$ ). A further reduction of the air temperature in the hothouse is achieved by opening the technological openings and exhaust aeration shafts (mode $I I$ ). Then additionally turn on the exhaust fan (if any), located in the exhaust aeration shaft (mode $I I I)$. The position of point $B$ on the line $B^{m}-B^{d}$ during the light period of the day depends on the ventilation rate $n, \mathrm{~h}^{-1}$, the ability of biomass to self-regulate the temperature around the plant. A ventilation rate changes from $n=5 \ldots 10 \mathrm{~h}^{-1}$ under the natural air-change to $n=25 \ldots 30 \mathrm{~h}^{-1}$ under the mechanical ventilation [1]. Therefore, the location of the point $B$ (on the $i$-d-diagram of the moist air) will strive along the line $B^{m}-$ $B^{d}$ to the point $B^{m}$ in a ratio of $1:(n-1)$.

So the area, bounded by the points $B_{1}^{m}-B_{1}-B_{1}^{d}-B_{2}^{d}-B_{2}-B_{2}^{m}$, characterizes the borders of temperature and humidity condition of the air in the daytime hours in the hothouse during the warm period of the year at the expense of natural and mechanical ventilation by the untreated atmospheric air and self-regulation of plants.

After exhaustion of the cooling effect of outdoor air to maintain the technological parameters of microclimate arises the need for artificial cooling of the air in the hothouses. Such a period of time usually occurs during the daylight hours, when the total solar radiation reaches $450 \mathrm{~W} / \mathrm{m}^{2}$ or more (from May till October).

Figure 2 shows the processes of changing the air state in the hothouse with the biomass during the operation of system of water aerosol cooling. After switching SWAC there is adiabatic cooling of the air in the volume of hothouse according $i_{\text {int }}=$ const to $\varphi=97 \ldots 98$ $\%$ (fig. 2 a process schematically shows to $\varphi=100 \%$ ) from the temperature $t_{i n t}$ to the temperature of the wet the roomette $t_{w . t}^{\text {int }}$, which corresponds to the parameters of the point $B$. Concurrently moisture content in the hothouse increases from $d_{B}$ to $d_{A}$ according to the relative humidity in the point $A(97 \ldots 98 \%)$. If the amount of the heat of solar radiation in the hothouse exceeds the amount of heat absorbed during evaporation of water aerosol droplets, so process of the air cooling is terminated at the point $C$ during the temperature $t_{C}$, the relative humidity $\varphi_{C}$ and the moisture content of air $d_{C}$.

The air temperature after its processing by SWAC to the point $A$ or to the point $C$ (fig. 2) may be reduced to a range of technologically necessary temperatures in the hothouse (beam $B-A$ ) or be above them (the beam $B-C$ ). Specific parameters of the air in the hothouse with volume $V_{h}, \mathrm{~m}^{3}$, during the ventilation rate $n, \mathrm{~h}^{-1}$, are determined by increment of its water content $\Delta d$, which depends on the flow rate of sprayed water $G_{s . w}$, $\mathrm{kg} / \mathrm{h}$, and air density $\rho_{\text {int }}, \mathrm{kg} / \mathrm{m}^{3}$ :

$$
\Delta d=d_{C}\left(d_{A}\right)-d_{B}=\frac{1000 \cdot G_{s . w}}{V_{h} \cdot n \cdot \rho_{i n t}} .
$$




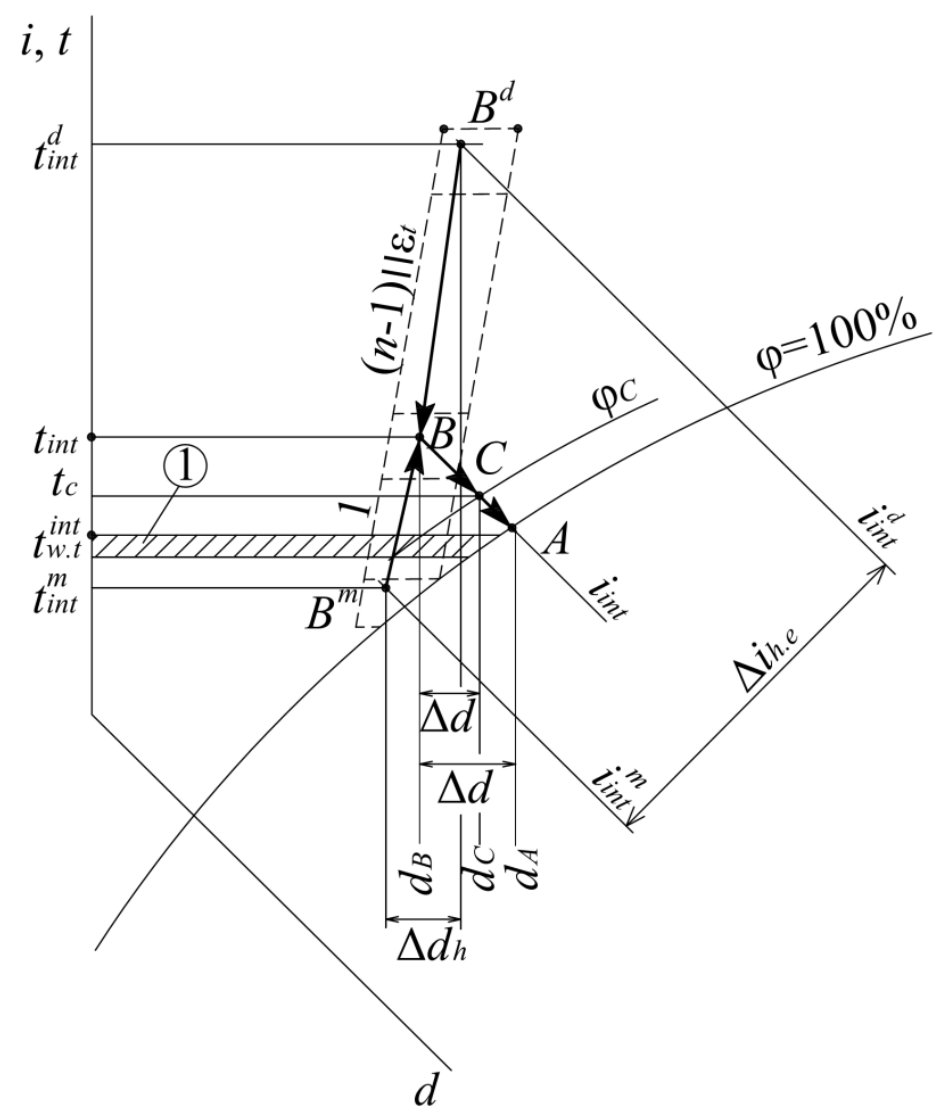

Fig. 2. The processes of changing the air state in the hothouse with the biomass:

1 - the area of technological temperatures in the hothouse

The reducing of intensity of solar radiation in the afternoon is accompanied by a decrease of internal air temperature. SWAC switched off, but the exhaust fan built into the shaft continues to operate, transoms and technological openings are opened. The parameters of internal air are transformed into the state of the point $B$, corresponding to the parameters before the activation the adiabatic cooling system. The relative humidity and moisture content of the air decrease and the temperature increases. It is this thermodynamic process is inevitable, because the heat capacity of the equipment in hothouses is negligible and plants can self-regulate the air parameters around themselves in the process of adaptive reactions during transpiration of moisture.

The process of removing the intensity of solar radiation in the day period after switching off SWAC and further regulation of the air parameters in the hothouses within a standardized technological values will be carried out by changing the position of the point $B$ on the line $B^{m}-B^{d}$. These processes are possible when changing the ventilation rate $n$ by switching - off the exhaust fan, opening - closing the technological openings and transoms. In the evening when the internal air temperature decreases to the design temperature in the hothouse and below all the technological openings and transoms are closed. 
The direction of the beam of the process on $i-d$-diagram $\varepsilon_{t}=\Delta i_{h . e} / \Delta G_{m . r}$. The total heat emissions in the hothouse $i_{\text {h.e }}$ are determined according to the intensity of insulation heat gains. Moisture release in the hothouse $\Delta G_{m . r}=\Delta d_{h} V_{h} \rho_{i n t}$ are composed of secretions of plants and evaporation from soil surface. Analysis of literature data and our field studies recommend during the peak of heat load for central part of Russia take $\varepsilon_{t}=$ $3700 \ldots 4800 \mathrm{~kJ} / \mathrm{kg}$.

As an indicator of the efficiency of removal of overheat for a day $(N=24 \mathrm{~h})$ during the period of the field studies was adopted a coefficient of probability of operation of cooling systems $K_{p r}^{d}$. Its value shows the share of the total number of hours for a day, which does not allow to exceed the internal air temperature in a hothouse relative to the design temperature:

$$
K_{p r}^{d}=(N-m) / N
$$

where $m$ - the number of hours of temperature rises for a day.

Figures 3 and 4 show generalized experimentally obtained temperatures in the hottest period of sunny day. The shaded part indicates the area of optimal temperatures of internal air for growing crops. Mode IV of operation of complex system of removal of overheat is not typical in practical terms and, therefore, has not been studied.

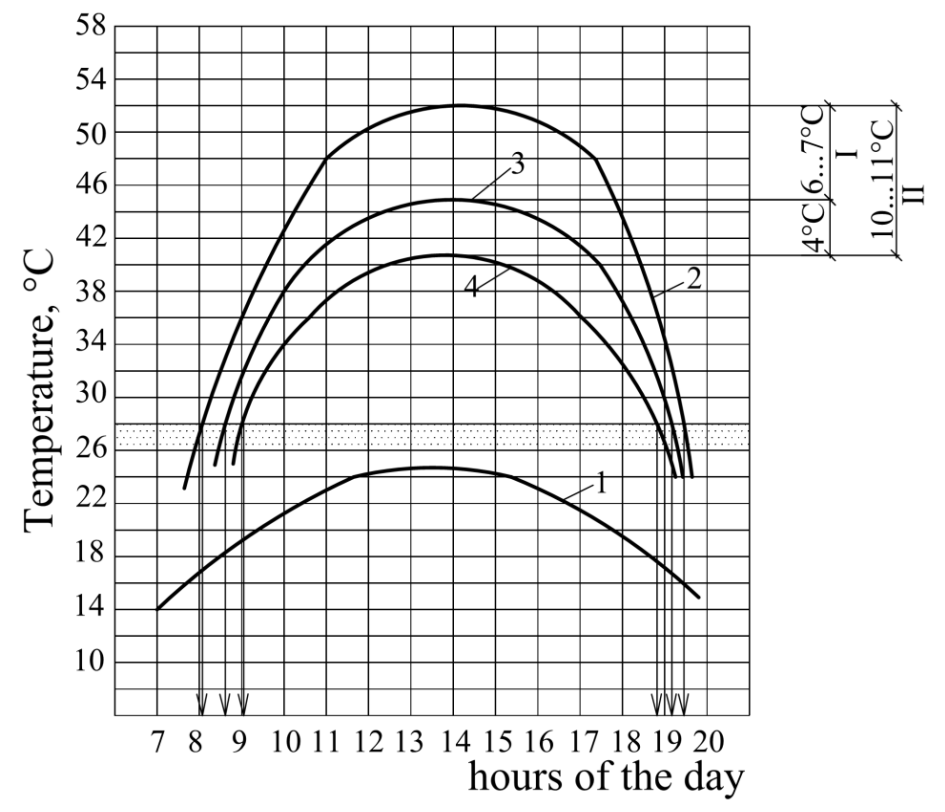

Fig. 3. Changing of air temperature in a hothouse during the period of fruiting during daylight hours: 1 - outdoor air; 2 - internal air without operation of systems of removal of overheat; 3 - operation of the systems of organized ventilation (mode $I$ ); 4 - co-operation of the systems of organized ventilation and active aeration (mode $I$ ) 


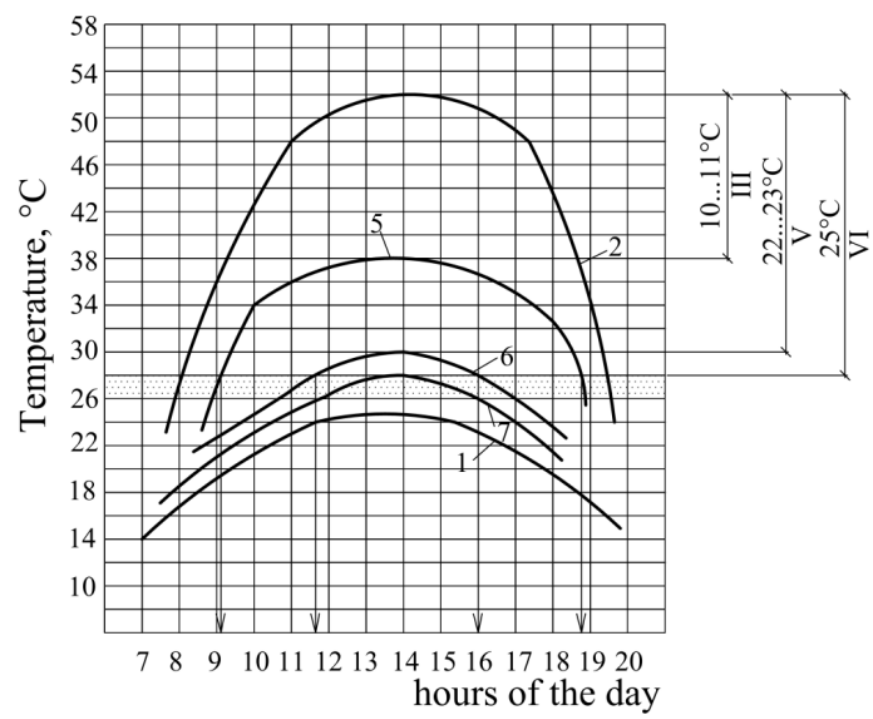

Fig. 4. Changing of air temperature in a hothouse during the period of fruiting during daylight hours: 1 - outdoor air; 2 - internal air without operation of systems of removal of overheat; 5 - co-operation of the systems of organized ventilation and mechanical ventilation (mode III); 6 - co-operation of the systems of organized ventilation and SWAC (mode $V$ ); 7 - co-operation of the systems of organized ventilation, active shaft or mechanical ventilation and SWAC (mode $V I$ )

The results of determining the values of a coefficient of probability of operation of cooling systems during the day $K_{p r}^{d}$ and quantitative indicators of reduce the temperature in each of the operating modes of the complex system of removal of overheat $\Delta t_{\text {int }}$ are shown in Table 1.

Table 1. Values $K_{p r}^{d}$ and $\Delta t_{\text {int }}$

\begin{tabular}{|c|c|c|c|c|c|}
\hline $\begin{array}{c}\text { Operating } \\
\text { modes }\end{array}$ & I & II & III & V & VI \\
\hline$\Delta t_{\text {int }},{ }^{\circ} \mathrm{C}$ & $6 \ldots 7$ & $10 \ldots 11$ & $14 \ldots 15$ & $22 \ldots 23$ & up 28 \\
\hline$K_{p r}^{d}$ & 0,567 & 0,60 & 0,63 & 0,833 & 1,0 \\
\hline
\end{tabular}

A coefficient of probability of temperature conditions in the hothouse during the warm period in the annual cycle $K_{p r}^{a n}$ is necessary to determine for the period of fruiting of tomatoes and cucumbers, which lasts from April $1^{\text {st }}$ to August $1^{\text {st }}$. The values of the coefficient are calculated by the formula:

$$
K_{p r}^{a n}=1-\left(N^{a n}-m^{a n}\right) / N^{a n}
$$

The number of days of fruiting for the central part of Russia is $K_{p r}^{a n} \approx 120$ days. The duration of the period of maintenance of maximum permissible internal air temperature $\left(t_{\text {int }}\right.$ $\left.\leq 28^{\circ} \mathrm{C}\right) m^{a n}$, days, in the hothouses from April to July, depending on the operation modes of systems of maintenance of parameters of technological microclimate calculated by figure 5 that are obtained as a result of field studies. Changing the temperature $t_{\text {int }}$ in the hothouse under the co-operation of SWAC with active shaft aeration and mechanical ventilation (mode $V I$ ) can be traced by the curve 6 . The maximum decrease of the air 
temperature in the hothouse during operation of complex system is $23 \ldots .25^{\circ} \mathrm{C}$. It is almost always provides the necessary temperature regime for all the phenological phases of vegetables, including the fruiting stage (April - July).

Therefore, the value $K_{p r}^{a n} \approx 1-(120-120) / 120 \approx 1,0$.
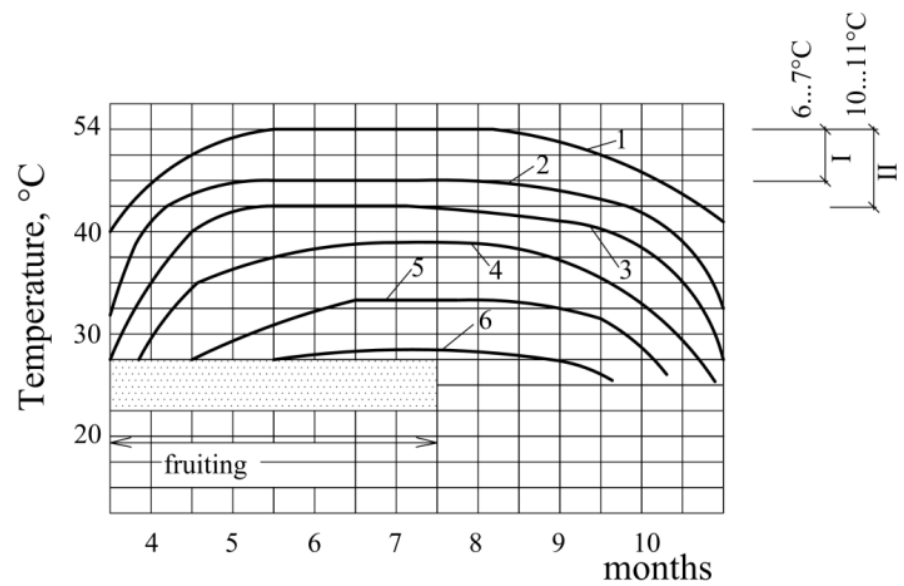

Fig. 5. Changing of air temperature in a hothouse during the period of fruiting: 1 - without operation of systems of removal of overheat; 2 - operation of systems of organized ventilation (mode $I$ ); 3 - cooperation of the systems of organized ventilation and active aeration (mode $I I) ; 4$ - co-operation of the systems of organized ventilation and mechanical ventilation (mode III); 5 -co-operation of the systems of organized ventilation, active aeration and SWAC (mode $V$ ) $6-$ co-operation of the systems of organized ventilation, active shaft or mechanical ventilation and SWAC (mode $V I$ )

The results of determining a coefficient of probability of the operating mode for the annual cycle of fruiting period are summarized in Table 2.

Table 2. The values of $K_{p r}^{a n}$ for the period of fruiting

\begin{tabular}{|c|c|c|c|c|c|}
\hline $\begin{array}{c}\text { Operating modes of } \\
\text { the complex system }\end{array}$ & $I$ & $I I$ & $I I I$ & $V$ & $V I$ \\
\hline$N^{a n}$, cyт. & 120 & 120 & 120 & 120 & 120 \\
$m^{a n}$, cyт. & 0 & 0 & 6 & 3,0 & 120 \\
$K_{p r}^{a n}$ & 0 & 0 & 0,05 & 0,25 & 1,0 \\
\hline
\end{tabular}

\section{Conclusion}

Graphic-analytical and field studies of the thermodynamic processes in the hothouses showed that the internal air temperature during the period of maximum heat gain from solar radiation can be reduced by $23 \ldots 25{ }^{\circ} \mathrm{C}$. The authors obtained quantitative values of coefficients of air temperature parameters in the hothouses during the warm period of the year for the climate of central part of Russia in the daily and annual cycles of operation of hothouses.

\section{Reference}

1. V.I. Bodrov, Nizhny Novgorod State University of Architecture and Civil Engineering, 623 (2008) 